\title{
Prevalence and factors associated with low birth weight in Axum and Laelay Maichew Districts, North Ethiopia: A comparative cross sectional study
}

\author{
Negassi Teklehaimanot ${ }^{1}$, Tesfay Hailu ${ }^{2}$, Huruy Assefa ${ }^{2,}$, \\ ${ }^{1}$ Tigray Health Bureau, PO. Box, 07 Mekelle, Tigray, Ethiopia \\ ${ }^{2}$ Department of Public Health, College of Health Sciences, Mekelle University, PO. Box, 1871 Mekelle, Ethiopia
}

\section{Email address:}

huruyame@yahoo.com (H. Assefa)

\section{To cite this article:}

Negassi Teklehaimanot, Tesfay Hailu, Huruy Assefa. Prevalence and Factors Associated with Low Birth Weight in Axum and Laelay Maichew Districts, North Ethiopia: A Comparative Cross Sectional Study. International Journal of Nutrition and Food Sciences. Vol. 3, No. 6, 2014, pp. 560-566. doi: 10.11648/j.ijnfs.20140306.21

\begin{abstract}
Background: Weight at birth is a good indicator of the newborn's chances for survival, growth, long-term health and psychosocial development. Low birth weight babies are significantly at risk of death, contributing to the high perinatal morbidity and mortality in Ethiopia. Therefore, the aimed of this study is to assess the prevalence and associated factors of Low Birth Weight in Axum and Laelay Maichew districts, Tigray, north Ethiopia. Method: An institution based comparative cross-sectional study using consecutive sampling technique was used to select a sample of 520 live birth neonates from both urban and rural districts. Data was collected from mothers' using a structured interview questionnaire. The data were entered in to Epi-Info and analyzed on SPSS. Means and standard deviations of birth weight were calculated using the t-test. The chisquare $\left(\mathrm{X}^{2}\right)$ test was computed to compare proportions of low birth weight with $95 \%$ Confidence Interval. Binary and multivariable logistic regression was used to identify the risk factors. Result: The prevalence of low birth weight was $9.9 \%$ and 6.3\% in Axum and Laelay Maichew districts, respectively. In Axum district (Urban): low birth weight was associated with inadequate $\mathrm{ANC}$ service utilization $[\mathrm{AOR}=0.29,95 \% \mathrm{CI}:(0.12,0.73)]$ and unwanted pregnancy $[\mathrm{AOR}=4.04,95 \% \mathrm{CI}:(1.17$, 13.90)]. Sex of the neonate [AOR=6.08, 95\% CI:(1.60, 23.07)] and pregnancy type [AOR=7.34, 95\% CI:(2.050, 26.292)] were also significantly associated with low birth weight in Laelay Maichew district (rural). Conclusion and Recommendation: The prevalence of low birth weight was $9.9 \%$ and $6.3 \%$ in Axum and Laelay Maichew districts, respectively. The burden of low birth weight deliveries in these areas are associated with inadequate ANC service utilization, unwanted pregnancy and female sex of the neonate which deserve goal oriented prenatal care and choice based family planning service provision by the respective health facilities.
\end{abstract}

Keywords: Low Birth Weight, Axum, Laelay Maichew, Ethiopia

\section{Introduction}

The World Health Organization (WHO) defines Low Birth Weight (LBW) as having a birth weight (BW) of less than 2500 gram irrespective of the gestational age of the neonate [1]. Low birth weight and preterm birth are major determinants of perinatal survival, infant morbidity and mortality as well as risk of developmental disabilities and illnesses throughout future lives [2]. Birth weight has emerged as the leading indicator of infant health and welfare and the fundamental focus of infant health policy [3].

Babies born with LBW are more likely to have health problems and slower development from immediately after birth to later in life $[2,5]$. They suffer from extremely high rates of morbidity and mortality from infectious disease, and underweight, stunting or wasting beginning in the neonatal period through childhood [6]. Low birth weight babies usually need extra hospital care, and there is a constant concern and uncertainty over future health outcomes [8].

An estimated 18 million babies worldwide are born each year with LBW; 9.3 million of them in South Asia and 3.1 million in sub-Saharan Africa [1]. Reducing the incidence of LBW by at least one third between 2000 and 2010 was a major goal of "A World Fit for Children" program of the United Nations [9]. Despite this, LBW remains a major 
public health problem in the world especially in many subSaharan African countries where the global and sub-Saharan African prevalence of LBW is $15.5 \%$ and from $13 \%$ to $15 \%$, respectively $[2,9]$. These figures are higher than the target of a reduction in the incidence of LBW to no more than $10 \%$ set by the World summit for children [2] and this much amount of LBW rate at term is a major public health problem [6] which represents scant progress, considering that babies born at LBW face the most severe risks [11] that contributes to 60 to $80 \%$ of all neonatal deaths [12].

Low birth weight stems primarily from the mother's poor nutrition and health over a long period of time, teenage pregnancy, high prevalence of infections, and pregnancy complications [14-16]. Low birth weight is also associated with many socio-economic factors such as place of residence, education, mothers' age and occupation, birth order, family income and many maternal conditions such as nutritional status, cigarette smoking and health status $[17,18]$.

These risk factors can be prevented by a lifespan approach (before, during, and after child birth) to the health of women that takes full account of socioeconomic and environmental as well as medical issues and public education campaigns [11] and also by some key preventive interventions like improved food intake of pregnant women, ante natal care (ANC), micronutrient supplementation, prevention and treatment of such infections as malaria, reduction of teenage pregnancy, and maternal education [9]. Despite the presence of these prevention options and efforts, LBW remains a formidable public health challenge for the $21^{\text {st }}$ century and more research is needed to illuminate how the many factors affecting LBW interact, because for every clear finding, there are numerous unanswered questions $[6,11]$.

Ethiopia, having an infant mortality rate of 59/1000 live births [19] has limited data on BW estimates as most deliveries take place at home leading to a highly biased maternal subjective inclusion of a "very small baby" in the reports. Previous survey in the country reported an increasing trend of LBW [20] and a study revealed a $22.5 \%$ prevalence of LBW among health institution deliveries in the south western part of the country [10]. Hence, this study aims to assess the prevalence and associated factors of LBW among neonates delivered at health facilities of Axum and Laelay Maichew districts, Tigray, north Ethiopia.

\section{Methods}

\subsection{Study Setting and Participants}

Institution based cross-sectional comparative study was conducted from February to April, 2013 among new born neonates of Axum (urban) and Laelay Maichew (rural) districts, north Ethiopia. Axum and Laelay Maichew districts are structured into four urban and fifteen rural kebeles. Based on projection the total population size of Axum and Laelay Maichew districts in 2012/13 are estimated to be 50,431 and 82,123 , respectively. Out of these 23,400 (46.4\%) and 27,031 $(53.6 \%)$ in Axum are males and females, respectively; and
40,897 (49.8\%) and 41,226 (50.2\%) in Laelay Maichew are males and females, respectively [19]. Child bearing age women (CBAW) make up about $23.5 \%$ of the population and $2.64 \%$ and $3.62 \%$ of them give live births annually in the urban and rural areas [19]. Axum district has one referral hospital and two health centers; and there are four health centers in Laelay Maichew district.

All health facilities [one referral hospital and 6 health centers] from each district were included in the study. From all health facilities, 520 study subjects were selected using a consecutive sampling technique [54] (including all eligible neonates) till the calculated sample size was achieved. The allocation to each health facility was done based on population proportion to size (PPS). To determine the sample size, double population proportion formula was used by assuming 9\% (urban) and 17\% (rural) prevalence of LBW [19], 95\% confidence level, $80 \%$ power, $5 \%$ margin of error and Odds Ratio (OR) of 2. Therefore, the total sample size was 520 individuals.

\subsection{Measurements}

A primary data were collected using a structured interview questionnaire adapted from related papers. Mothers were asked about their obstetric and gynecologic histories, morbidity experiences and other related information. Gestational age was estimated by the number of days between the first day of the last menstrual period (LMP) and date of birth expressed in completed weeks after LMP as recorded in the maternity delivery log.

Neonatal weight was measured to the nearest $0.1 \mathrm{~kg}$ using digital scales (SECA). Both interviews and weight measurements were done by trained midwives. Seven diploma level midwives [speak the local language (Tigrigna)] were assigned in the health facilities and two nurse supervisors were recruited from both district health offices. The interview was conducted at the health facility after the mother gave birth and the neonatal weight was measured after birth (within two hours of delivery).

The English version of the questionnaire was translated in to local language (Tigrigna) for better understanding by both data collectors and respondents. Consistency was checked by re-translating the Tigrigna version back to English by another individual who is expertise in both languages. The data collectors and supervisors were trained for two days by the investigators prior to the data collection time. Pretest was done on $5 \%$ of the sample just before the actual day of data collection.

The quality of data was ensured during collection, coding, entry and analysis. During the data collection time, adequate supervision and follow up was provided to the data collectors and were checked on $10 \%$ of the respondents and neonates. Weighing scales were checked and adjusted at zero level between each measurement and values to the nearest $100 \mathrm{gm}$ were considered. Codes was given to the questionnaire during the time of data collection so that any identified errors was traced back using the codes. 


\subsection{Data Analysis}

The data was entered in to Epi Info version 7.1.1.14 statistical software. The data was thoroughly cleaned before analysis by checking frequency distribution of each variable and then transferred to SPSS version 16.0 statistical software for analysis.

Descriptive statistics such as mean $\left({ }_{-} \mathrm{SD}\right)$ were calculated to compare group features. The student's t-test and $\mathrm{X}^{2}$ test (Chi square) were computed to show whether the difference is significant or due to chance at $\mathrm{p}<0.05$ and to compare proportions of LBW with the $95 \%$ confidence level, respectively. Logistic regression analysis was carried out to determine the effect of factor(s) on the outcome variable and to control possible confounders. Factors with a $p$-value $<0.05$ in the bivariate analysis were further entered into the multivariate analysis to control for potential confounders. Crude and adjusted odds ratio with $95 \%$ confidence interval were calculated.

\subsection{Ethical Consideration}

The study was conducted after approval by the IRB (Institutional Review board) of College of Health Sciences, Mekelle University. Official letters were written from the
Department of Public Health, College of Health Sciences and Tigray Regional Health Bureau to respective officials. Permission to conduct this study was also be obtained from the medical director's office of each health facility. Informed verbal consent was obtained from study participants in their local language after explaining the purpose of the study, potential risks and benefits of partaking in the study, and the right to withdraw from the study at any time. The participants were also assured about the confidentiality of the data.

\section{Result}

\subsection{Socio-Demographic Characteristics}

A total of 506 neonates/mothers (253 neonates from each district) were involved in this study with a similar response rate of $97.3 \%$. The mean $( \pm \mathrm{SD})$ age of the mothers were $24.93( \pm 4.72)$ years and $27.79( \pm 6.7)$ years in Axum (urban) and Laelay Maichew (rural) districts, respectively. About 181 (71.5\%) and $142(56.1 \%)$ of the mothers of ages 20-34 years were from Axum and Laelay Maichew. All of the mothers were Tigray in ethnics in both districts. Majority of the mothers were married [238 (94.1\%) in Axum and 245(96.8\%) in Laelay Maichew] and Orthodox Christians [208 (82.2\%) in Axum and 250(98.8\%) in Laelay Maichew]. (Table1)

Table 1. Socio-demographic characteristics of study participants of Axum ( $n=253$ ) and Laelay Maichew ( $n=253)$ districts, Tigray, north Ethiopia, August 2013

\begin{tabular}{|c|c|c|c|}
\hline \multirow{3}{*}{ Variables } & & \multicolumn{2}{|l|}{ Districts } \\
\hline & & Axum (Urban) & Laelay Maichew (Rural) \\
\hline & & Freq. (\%) & Freq. $(\%)$ \\
\hline \multirow{3}{*}{ Age of the mother (in years) } & $<20$ & $60(23.7)$ & $58(22.9)$ \\
\hline & $20-34$ & $181(71.5)$ & $142(56.1)$ \\
\hline & $35+$ & $12(4.7)$ & $53(20.9)$ \\
\hline \multirow{2}{*}{ Religion } & Orthodox Christian & $208(82.2)$ & $250(98.8)$ \\
\hline & Muslim & $45(17.8)$ & $3(1.2)$ \\
\hline \multirow[t]{2}{*}{ Ethnicity } & Tigray & $253(100)$ & $253(100)$ \\
\hline & Married & $238(94.1)$ & $245(96.8)$ \\
\hline \multirow{3}{*}{ Marital status } & Divorced & $14(5.5)$ & $5(2)$ \\
\hline & Separated & $0(0.0)$ & $1(0.4)$ \\
\hline & Never Married & $1(0.4)$ & $2(0.8)$ \\
\hline \multirow{5}{*}{ Educational status } & unable to read and write & $25(9.9)$ & $114(45.1)$ \\
\hline & Read and write & $11(4.3)$ & $30(11.9)$ \\
\hline & $1-6$ & $26(10.3)$ & $20(7.9)$ \\
\hline & $7-12$ & $142(56.1)$ & $74(29.2)$ \\
\hline & College and above & $49(19.4)$ & $15(5.9)$ \\
\hline \multirow{7}{*}{ Occupation } & House Wife & $150(59.3)$ & $59(23.3)$ \\
\hline & Farmer & $10(4.0)$ & $162(64)$ \\
\hline & Government Employee & $29(11.5)$ & $9(3.6)$ \\
\hline & Private Employee & $27(10.7)$ & $6(2.4)$ \\
\hline & Merchant & $9(3.6)$ & $6(2.4)$ \\
\hline & House Maid & $10(4.0)$ & $3(1.2)$ \\
\hline & Student & $18(7.1)$ & $8(3.2)$ \\
\hline
\end{tabular}

\subsection{Medical and Obstetric Characteristics}

Almost half $120(47.4 \%)$ and about one third $76(30.0 \%)$ of the mothers were primiparous in Axum and Laelay Maichew districts, respectively. Of the multiparous 133 $(52.6 \%)$ and $177(70 \%)$ individuals were from Axum and Laelay Maichew districts. With regard to the type of current pregnancy; $209(82.6 \%)$ and $185(73.1 \%)$ of the pregnancies were wanted and planned in Axum and Laelay Maichew districts, respectively. (Table 2)

All the participants in Axum district and 97.2\% in LaelayMaichew district had history of ANC follow up, respectively. Of which $195(77.1 \%)$ and $128(50.6 \%)$ had at least four visits during the current pregnancy in Axum and LaelayMaichew districts, respectively. Majorities of the respondents were booked for ANC follow up in the first and second trimester (244 (96.4\%) and $211(83.4 \%)$ from Axum and Laelay-Maichew districts, respectively). (Table 2) 
In this study, majority $219(86.6 \%)$ and $229(90.5 \%)$ of the pregnant women were supplemented with Iron/Folic acid during the ANC follow up from Axum and Laelay-Maichew districts, respectively. Nearly all [247 (97.6\%) of Axum and $242(95.7 \%)$ of Laelay-Maichew districts] of the women said they were given dietary counseling during the current pregnancy and in addition 245 (96.8\%) and $223(88.1 \%)$ of the respondents were taking additional nutrients during the current pregnancy in Axum and Laelay-Maichew districts, respectively. (Table 2)

Table 2. Medical and obstetric characteristics of study participants of Axum ( $n=253)$ and Laelay Maichew (n=253) Districts, Tigray, north Ethiopia, August 2013

\begin{tabular}{|c|c|c|c|}
\hline \multirow{2}{*}{ Variables } & & \multirow{2}{*}{$\begin{array}{l}\text { Axum (Urban) } \\
\text { Freq. (\%) } \\
\end{array}$} & \multirow{2}{*}{$\begin{array}{l}\text { Laelay-Maichew (Rural) } \\
\text { Freq. (\%) }\end{array}$} \\
\hline & & & \\
\hline \multirow{3}{*}{ Parity } & 1 & $120(47.4 \%)$ & $76(30.0 \%)$ \\
\hline & $2-3$ & $100(39.5 \%)$ & $91(36.0 \%)$ \\
\hline & $>4$ & $33(13.0 \%)$ & $86(34.0 \%)$ \\
\hline \multirow{3}{*}{ Pregnancy interval } & $<3$ & $86(63.7 \%)$ & $94(52.2 \%)$ \\
\hline & $3-4$ & $19(14.1 \%)$ & $45(25.0 \%)$ \\
\hline & $>5$ & $30(22.2 \%)$ & $41(22.8 \%)$ \\
\hline \multirow{2}{*}{ Small baby at previous birth } & Yes & $9(3.6 \%)$ & $16(6.3 \%)$ \\
\hline & No & $244(96.4 \%)$ & $237(93.7 \%)$ \\
\hline \multirow{3}{*}{ Pregnancy type } & Wanted and Planned & $209(82.6 \%)$ & $185(73.1 \%)$ \\
\hline & Wanted and Unplanned & $28(11.1 \%)$ & $33(13.0 \%)$ \\
\hline & Unwanted and Unplanned & $16(6.3 \%)$ & $35(13.8 \%)$ \\
\hline \multirow{3}{*}{ Number of ANC visits during this pregnancy } & 0 & $0(0 \%)$ & $7(2.8 \%)$ \\
\hline & $1-3$ & $58(22.9 \%)$ & $118(46.6 \%)$ \\
\hline & $4^{+}$ & $195(77.1 \%)$ & $128(50.6 \%)$ \\
\hline \multirow{3}{*}{ Trimester of first ANC visit } & $1^{\mathrm{st}}$ & $54(21.3 \%)$ & $39(15.4 \%)$ \\
\hline & $2^{\text {nd }}$ & $190(75.1 \%)$ & $172(68.0 \%)$ \\
\hline & $3^{\text {rd }}$ & $9(3.6 \%)$ & $35(13.8 \%)$ \\
\hline \multirow{2}{*}{ Iron/Folic acid supplementation } & Yes & $219(86.6 \%)$ & $229(90.5 \%)$ \\
\hline & No & $34(13.4 \%)$ & $24(9.5 \%)$ \\
\hline \multirow{2}{*}{ Dietary counseling during pregnancy } & Yes & $247(97.6 \%)$ & $242(95.7 \%)$ \\
\hline & No & $6(2.4 \%)$ & $4(1.6 \%)$ \\
\hline \multirow{2}{*}{ Took additional nutrition during pregnancy } & Yes & $245(96.8 \%)$ & $223(88.1 \%)$ \\
\hline & No & $4(1.6 \%)$ & $19(7.5 \%)$ \\
\hline
\end{tabular}

Note: If a woman is her first delivery, she was included as parity=1

Table 3. Factors associated with LBW at Axum and Laelay Maichew districts, Tigray, north Ethiopia (n=253), August 2013

\begin{tabular}{|c|c|c|c|c|c|}
\hline \multicolumn{6}{|l|}{ Axum district (Urban) } \\
\hline Variables & & LBW & Total & COR (95\% CI) & $\operatorname{AOR}(95 \%$ CI) \\
\hline \multirow{2}{*}{ Sex of the neonate } & Male & 7 & 119 & 1 & \\
\hline & Female & 18 & 134 & $2.483(0.999,6.173)$ & $2.123(0.798,5.646)$ \\
\hline \multirow{3}{*}{ ANC follow up } & $1-3$ & 13 & 58 & 1 & \\
\hline & $4+$ & 12 & 195 & $0.227(0.097,0.531)$ & $0.291(0.115,0.734)^{* *}$ \\
\hline & Wanted and Planned & 18 & 209 & 1 & \\
\hline \multirow[t]{3}{*}{ Pregnancy type } & Wanted and Unplanned & 1 & 28 & $0.393(0.050,3.064)$ & $0.362(0.044,2.995)$ \\
\hline & Unwanted and Unplanned & 6 & 16 & $6.367(2.074,19.54)$ & $4.040(1.174,13.906)^{*}$ \\
\hline & Breakfast and lunch & 2 & 4 & 1 & \\
\hline \multirow[t]{2}{*}{ Diet intake per 24 hours } & Breakfast, lunch and dinner & 8 & 55 & $0.17(0.021,1.388)$ & $0.159(0.018,1.427)$ \\
\hline & $\begin{array}{l}\text { Beak fast, lunch, snack and dinner } \\
\text { Laelay Maichew District (Rural) }\end{array}$ & 15 & 194 & $0.084(0.011,0.638)$ & $0.14(0.017,1.170)$ \\
\hline Variables & & LBW & Total & $\operatorname{COR}(95 \% \mathrm{CI})$ & $\mathrm{AOR}(95 \% \mathrm{CI})$ \\
\hline \multirow{2}{*}{ Sex of the neonate } & Male & 3 & 133 & 1 & \\
\hline & Female & 13 & 120 & $5.265(1.462,18.958)$ & $6.081(1.603,23.066)^{* *}$ \\
\hline \multirow{3}{*}{ Number of ANC follow up } & 0 & 2 & 7 & 1 & \\
\hline & $1-3$ & 9 & 118 & $0.206(0.035,1.218)$ & $0.45(0.054,3.751)$ \\
\hline & $4+$ & 5 & 128 & $0.102(0.016,0.658)$ & $0.248(0.026,2.326)$ \\
\hline \multirow{3}{*}{ Pregnancy type } & Wanted and Planned & 6 & 185 & 1 & \\
\hline & Wanted and Unplanned & 3 & 33 & $2.983(0.708,12.577)$ & $4.165(0.923,18.799)$ \\
\hline & Unwanted and Unplanned & 7 & 35 & $7.458(2.336,23.813)$ & $7.341(2.050,26.292)^{* *}$ \\
\hline
\end{tabular}

\subsection{Prevalence of $\mathrm{LBW}$}

In this study, the prevalence of LBW was $9.9 \%[\mathrm{n}=25,95 \%$ CI: $(0.96,1.62)]$ and $6.3 \%[n=16,95 \%$ CI: $(0.52,1.13)]$ in Axum and Laelay Maichew districts. The mean $( \pm \mathrm{t} d)$ birth weights of the neonates were $3055( \pm 556)$ and $3188( \pm 554)$ grams in Axum and Laelay Maichew districts, respectively. Even though the prevalence of the urban (Axum) was higher than the prevalence of the rural (Laelay-Maichew); it was not statistically significant $\left(\mathrm{X}^{2}=2.150, \mathrm{p}\right.$-value $\left.=0.143\right)$.

The prevalence of LBW is $5.9 \%$ in male births and $13.4 \%$ 
in female births in Axum district and $2.3 \%$ in male births and $10.8 \%$ in female births in Laelay-Maichew district. Thus, there is a significantly higher proportion of LBW in female babies than male babies in Axum $\left[\mathrm{X}^{2}=4.035\right.$, P-value $\left.=0.045\right]$ and Laelay-Maichew $\left[\mathrm{X}^{2}=7.835\right.$, $\mathrm{p}$-value $\left.=0.05\right]$ districts.

\subsection{Factors Associated with Low Birth Weight (LBW)}

In binary logistic regression: Sex of the neonate, ante natal care follow up, Pregnancy type and Diet intake per 24 hours were significantly associated with low birth weight in Axum district and sex of the neonate, ante natal care follow up and pregnancy type were significantly associated with low birth weight in Laelay Maichew district.

Significant variables in the binary logistic regression were entered in to multivariate logistic regression. And in the multivariate logistic regression: only ante natal care follow up and Pregnancy type were significantly associated with birth low weight in Axum district and sex of the neonate and pregnancy type were significantly associated with low birth weight in Laelay Maichew district.

Mothers who have had a history of greater than or equal to four ANC follow up were $71 \%$ less likely to deliver LBW babies when compared to those who have attended greater than or equal to three times [AOR $=0.29,95 \% \mathrm{CI}:(0.12$, 0.73)]. (Table 3)

Additionally, mothers who had unwanted and unplanned pregnancies were 4 times more likely to have LBW than those who had wanted and planned pregnancies $[\mathrm{AOR}=4.04$, 95\% CI: $(1.17,13.90)]$. (Table 3)

Female new born neonates were 6 times more likely to have $\mathrm{LBW}$ than their male counter parts $[\mathrm{AOR}=6.08,95 \% \mathrm{CI}$ : (1.60, 23.07)]. Additionally, mothers with unwanted and unplanned pregnancies were more than 7 times more likely to deliver LBW neonates than those who have had wanted and planned pregnancies $[\mathrm{AOR}=7.34,95 \% \mathrm{CI}:(2.050,26.292)]$. (Table 4)

\section{Discussion}

Globally birth weight has been accepted as single most important determinant of future chances of survival, healthy growth, freedom from morbidities and mortalities of infants. Low birth weight is a widely used indicator of new-born health. Factors associated with LBW are considered as determinants or predictors and their presence in a particular woman indicates an increased chance of bearing a LBW neonate. This prospective institution based comparative study presents the report of 506 birth episodes (253 from urban and 253 from rural) from Axum and Laelay Maichew districts, Tigray, north Ethiopia.

The prevalence of LBW in urban $(9.9 \%)$ is in line with Ethiopian demographic and health survey 2011 (9.1\%) and Tigray (10.1\%) [19] and a study conducted in Gambia $(10.5 \%)$ [39]. Unlike the urban area, the prevalence of LBW in rural $(6.3 \%)$ is found to be lower than the report of EDHS 2011 for the rural of Ethiopia (17.0\%) [19]. But the prevalence of LBW of the study in both urban and rural is lower than the studies conducted by WHO (15.5\%) and UNICEF $(13 \%$ to $15 \%)$ [9, 12]. The results of this study was also lower than some other institutional based studies in South Western Ethiopia (22.5\%) [10], Zimbabwe (16\%) [38] and India (22.9\%) [27]. This difference may be explained by the time gap between these studies and seasons of the year as birth weight may have seasonal variations [55] and also the prevalence of LBW may vary between and within geographical regions [1]. Other reasons might be, different study areas and study designs, influence of different risk factors were different, and health service utilizations might also be different.

However, this study found out a higher prevalence of LBW compared to other hospital based studies in Ethiopia ranging between 5.6\% and 8.6\% [44, 45] and in Qatar (6.7\%) [56] and in Iran $(8.8 \%$ and $6.3 \%)$ [34, 57]. It is also slightly higher than the prevalence of LBW in Egypt (6.2\% in 2005 and $7.3 \%$ in 2008) [58].

Differences between urban and rural settings in the current study of LBW showed higher prevalence in the urban (Axum). This is in agreement with the study done in Egypt [58] whereas, the proportions of LBW varied positively with the urbanization rate and negatively with rate of participation in the workforce. The reverse has been documented in countries such as India, where, the rate was $15.9 \%$ in rural and $10.8 \%$ in urban areas [59].

In urban area (Axum), inadequate ANC service utilization and unwanted pregnancies were independently and significantly associated with LBW. Mothers who have had a history of greater than or equal to four ANC follow up were $71 \%$ less likely to deliver LBW babies when compared to those who have attended greater than or equal to three times. This may be attributed to the beneficial impact of ANC on pregnancy outcome, either through the detesting and treatment of complications or by contributing to the reduction of modifiable maternal risk factors by providing an array of available medical, nutritional and educational interventions which might be intended to reduce the risk of LBW and other adverse pregnancy outcomes. This is in agreement with studies conducted in Ethiopia [13, 18, 43] and in India [24].

The other risk factor for giving birth to a LBW is the mother's unwanted pregnancy. Newborn neonates from unwanted and unplanned pregnancies were 4 times more likely than those from wanted and planned pregnancies to be of LBW. This is in agreement with studies conducted in Ecuador [61], Iran [62] and other systemic reviews [60]. The mechanism by which pregnancy intention status affects birth weight is not yet fully understood. Unwanted pregnancy may contribute to LBW by means of maternal behaviors such as nonuse or delayed initiation of prenatal care [63]. However, this study revealed an independent association between unwanted pregnancy and LBW after controlling other factor. Neonates from unwanted pregnancies may also have been more likely to be low in birth weight because their mothers ate a less nutritious diet than women with planned pregnancies and gained inadequate weight during pregnancy [59]. 
Also in rural (Laelay Maichew), sex of the newborn and unwanted pregnancy was significantly and independently associated with LBW. Female newborns were 6 times more likely to have LBW than their male counter parts. This is in agreement with studies conducted in Ethiopia [43], Sudan [42] and Iran [35].

New born neonates from women with unwanted and unplanned pregnancies were more than 7 times more likely to be of LBW than those from wanted and planned pregnancies. This may be explained by considering that intended pregnancy which results in a healthy childbirth from a healthy mother might be occurred based on the accurate and conscious decision and according to the physical, mental, economic, social, and cultural status. This result is in agreement with studies conducted in Ecuador [61], Iran [62] and a systemic review of other studies [60].

This study clearly shares the limitations of cross-sectional studies and hence does not show seasonal variations of LBW. Additionally, being conducted in health facilities, the study participants can hardly be restricted to those who have access to the respective health institutions. This study did not consider some potential risk factors for LBW such as placental factors, congenital syndromes and intra uterine infections.

\section{Conclusion}

In this study, there is a high prevalence of LBW compared to similar institution based studies in Ethiopia. Low birth weight was associated with sex of the neonate, inadequate ANC service utilization and unwanted pregnancy in both urban and rural area of the study.

\section{Recommendation}

Intensive community awareness raising and demand creation activities should be done at the grass root level through sustained community involvement by the district health offices and their respective health facilities to avoid unwanted pregnancies by providing choice based family planning services. The regional health bureau should strengthen the newly focused goal oriented ANC service utilization by pregnant women as it can improve birth out comes. It needs further research studies including actors such as home delivery, placental factors and seasonal variations.

\section{List of Abbreviations}

$\mathrm{LBW}=$ low birth weight, $\mathrm{BW}=$ birth weight, $\mathrm{OR}=$ Odds Ratio, $\mathrm{CI}=$ Confidence interval, $\mathrm{ANC}=$ Antenatal Care, PPS $=$ Population Proportion to Size, LMP $=$ Last Menstrual Period, $\mathrm{SD}=$ Standard Deviation, $\mathrm{COR}=$ Crude Odds Ratio, AOR $=$ Adjusted Odds Ratio.

\section{Authors' Contributions}

NT designed the study, performed the statistical analysis and participated in drafting the manuscript. TH participated in the study design, implementation of the study, and participated in drafting the manuscript. HA participated in the study design, implementation of the study, and drafted the manuscript. All authors contributed to the data analysis, read and approved the final manuscript.

\section{Acknowledgements}

We are very grateful to Mekelle University College of Health Sciences, Tigray Health Bureau for their technical and financial support of this study. We would also like to thank all mothers who participated in this study and their commitment in responding to our questions.

\section{References}

[1] UNICEF: Low Birth Weight New York, USA: United Nations Children's Fund; 2001.

[2] WHO: Low Birth Weight; Country, Regional and Global Estimates. Geneva, Switzerland \& New York, USA: World Health Organization \& United Nations Children's Fund 2004.

[3] Badshah S ML, McKelvie K, Payne R, Lisboa PJ. : Risk factors for low birth weight in the public hospitals at Peshawar. BMC Public Health 2008, 4(8):197.

[4] Matsuo H.: The health consequences of low birth weight. Literature review and critique. Institut de démographie. . Available http://1301045100/cps/ucl/doc/sped/documents/dt23pdf (Accessed on 09-10-2012).

[5] L. PJaK: Low Birth weight. Nutrition Policy. Dhaka, Bangladesh Geneva, Switzerland: World Health Organization (Available http://wwwunscnorg/layout/modules/resources/files/policypaper-No 18pdf (Accessed on 28-09-2012) 2000.

[6] Shrimpton R.: Preventing low birthweight and reduction of child mortality. Trans R Soc Trop Med Hyg 2003, 97(1):39-42.

[7] UNICEF: A World fit for children statistical review. New York, USA: United Nations Children's Fund 2007.

[8] Annie E : Casey Foundation. Kids count indicator brief preventing low birth weight. Available at http://wwwaecforg//mediapubs/initiatives/KIDS\%20countindicatorBriefPreventin gLowBirthWeightpdf (Accessed on 06-10-2012) 2009.

[9] WHO: Guide lines on optimal feeding of low birth weight infants in low and middle income countries. Geneva, Switzerland: World Health Organization 2011.

[10] Centers for Disease Control and Prevention and World Food Programme : Measuring and Interpreting Malnutrition and Mortality. Rome, Italy. 2005.

[11] UNICEF: Reduction of Low Birth Weight. Kathmandu, Nepal. United Nations Children's Fund - Regional Office for South Asia 2002.

[12] World Bank: Repositioning Nutrition as Central to Development, A Strategy for Large Scale Action. Washington DC, USA 2006. 
[13] Gebremariam A: Factors predisposing to low birth weight in Jimma Hospital, South Western Ethiopia. East African Medical Journal 2005, 82(11):554-558.

[14] Siza JE: Risk factors associated with low birth weight of neonates among pregnant women attending a referral hospital in northern Tanzania. Tanzania Journal of Health Research 2008, $10(1): 1-8$

[15] Central statistical Agency: Ethiopia Demographic and Health Survey. Central Statistical Agency and ORC Macro 2011.

[16] Central statistical Agency: Ethiopia Demographic and Health Survey. Central Statistical Agency and ORC Macro 2005.

[17] Tema T: Prevalence and determinants of low birth weight in Jimma zone, southwest Ethiopia. East African Medical Journal 2006, 83(7):366-371.

[18] Elder S: ILO school-to-work transition survey: A methodological guide. 2009. (http://www.ilo.org/wcmsp5/groups/public/@ed_emp/docume nts/instructionalmaterial/wcms_140859.pdf)

[19] Jammeh, A., Sundby, J. and Vangen, S: Maternal and obstetric risk factors for low birth weight and preterm birth in rural Gambia: a hospital-based study of 1579 deliveries. Open Journal of Obstetrics and Gynecology 2011, 1, 94-103.

[20] Mduduzi N, Mbuya1M, Bernard C, Mishra V.: Biological, Social, and Environmental Determinants of Low Birth Weight and Stunting among Infants and Young Children. February 2010, 7:10-14.

[21] Metgud CS NV, Mallapur MD: Factors affecting birth weight of a newborn. PLoS ONE 2012, 7(7): 01-04.

[22] Fikre Enquoselassie AM: Changes in birth-weight of Hospitaldelivered neonates in Addis Ababa. Ethiop J Health Dev 2000, 14(2):169-176

[23] Tegegne BA, FE, LY: Birth to pregnancy interval and its effect on perinatal outcomes in Addis Ababa, Ethiopia. Ethiopian Journal of Reproductive Health 2010, 4(37-51).

[24] Nekatibeb G GMA: Analysis of birth weight in Metu Karl hospital: South West Ethiopia. Ethiop Med J 2007, 45(2):195202.

[25] Abdulbari Bener KMKS, Mohammad T. Yousafzai,Najah M. Saleh: Pattern of Maternal Complications and Low Birth Weight: Associated Risk Factors among Highly Endogamous Women. ISRN Obstetrics and Gynecology 2012.
[26] Golestan M AKS, Fallah R.: Prevalence and risk factors for low birth weight in Yazd, Iran. Singapore Med J 2011, 52(10):730-3.

[27] Mirzarahimi M. HS, Ahmad P., and Alijahan R: Prevalence and risk factors for low birth weight in Ardabil, Iran. Iranian Journal of Neonatology 2013, 4(1):18-23.

[28] Elarab H: Epidemiological study of determinants of low birth weight in Egypt. The Egyptian Journal of Community Medicine 2011, 29(2):1-15.

[29] Kramer MS: Determinants of low birth weight: Methodological assessment and meta-analysis. Bull World Health Organ 1987, 65(5):663-737.

[30] Ezugwu E: Singleton low birth weight babies at a tertiary hospital in Enugu, South East Nigeria. The Internet Journal of Gynecology and Obstetrics 2010, 14(1).

[31] Berihun Megabiaw Zeleke MZ, NM: Incidence and correlates of low birth weight at a referral hospital in Northwest Ethiopia Pan African Medical Journal 2012, 12:4.

[32] Jayant D.; Phalke DB.; Bangal VB.; Peeyuusha D SB: Maternal risk factors for low birth weight neonates. National Journal of Community Medicine 2011, 2(3):396-7.

[33] Eggleston E, Kotelchuck M: Unintended Pregnancy and Low Birth weight in Ecuador. 2001, 91(5):808-10.

[34] Rafati S., Borna H., Akhavirad M., and Fallah F: Maternal determinants of giving birth to low-birth-weight neonates. Arch Iranian Med 2005, 8(4):277-281.

[35] Shah P. BT, Ohlsson A., Beyene J., Scott F., and Frick C.: Intention to Become Pregnant and Low Birth Weight and Preterm Birth. Maternal and Child Health Journal 2011, 15(2):205-216.

[36] Eggleston E. Unintended pregnancy and women's use of prenatal care in Ecuador. SocSci Med. 2000, 51:1011-1018.

[37] Elhassan M Elhassan AOA, Abderahuim D Haggaz, Magid S Abubaker and Ishag Adam: Anaemia and low birth weight in Medani, Hospital Sudan. BMC Research Notes 2010, 3(181).

[38] Delaram MA, Alireza: Prevalence of Low Birth Weight and its Related Factors in Shahr-e-Kord J Reprod Infertil 2008, 9(3):263-270. 